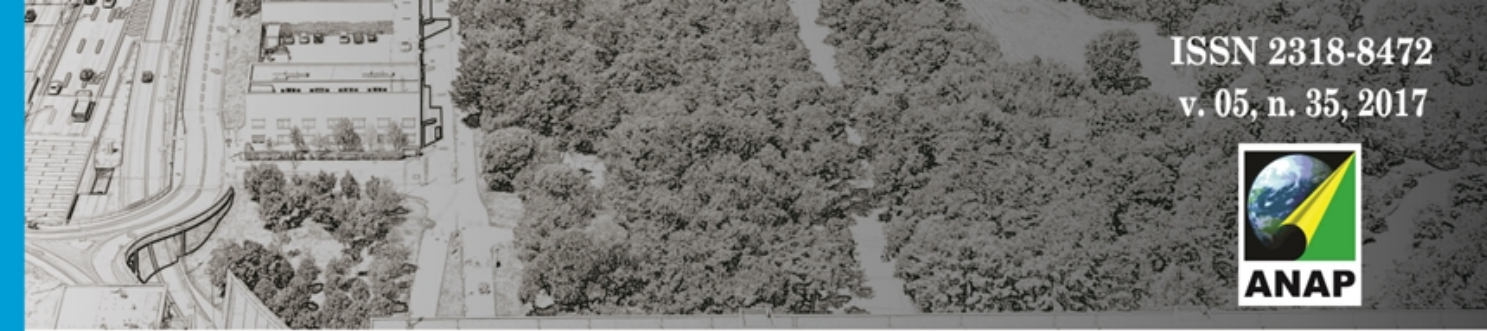

Gerenciamento de Cidades

National Journal of Cities Managemen

\title{
Parques Urbanos na promoção da Qualidade de Vida Estudo de caso em Passo Fundo, RS
}

\author{
Urban Parks in the promotion of Quality of Life: \\ Case study in Passo Fundo, RS
}

Parques Urbanos en la promoción de la Calidad de Vida:

Estudio de caso en Passo Fundo, RS

Mirian Carasek

Professora Mestre, UPF, Brasil

miriancarasek@upf.br

\section{Evanisa Fátima Reginato Quevedo Melo \\ Professora Doutora, UPF, Brasil evanisa@upf.br}

Ricardo Henryque Reginato Quevedo Melo

Doutorando, UFRGS, Brasil

ricardohquevedo@gmail.com 






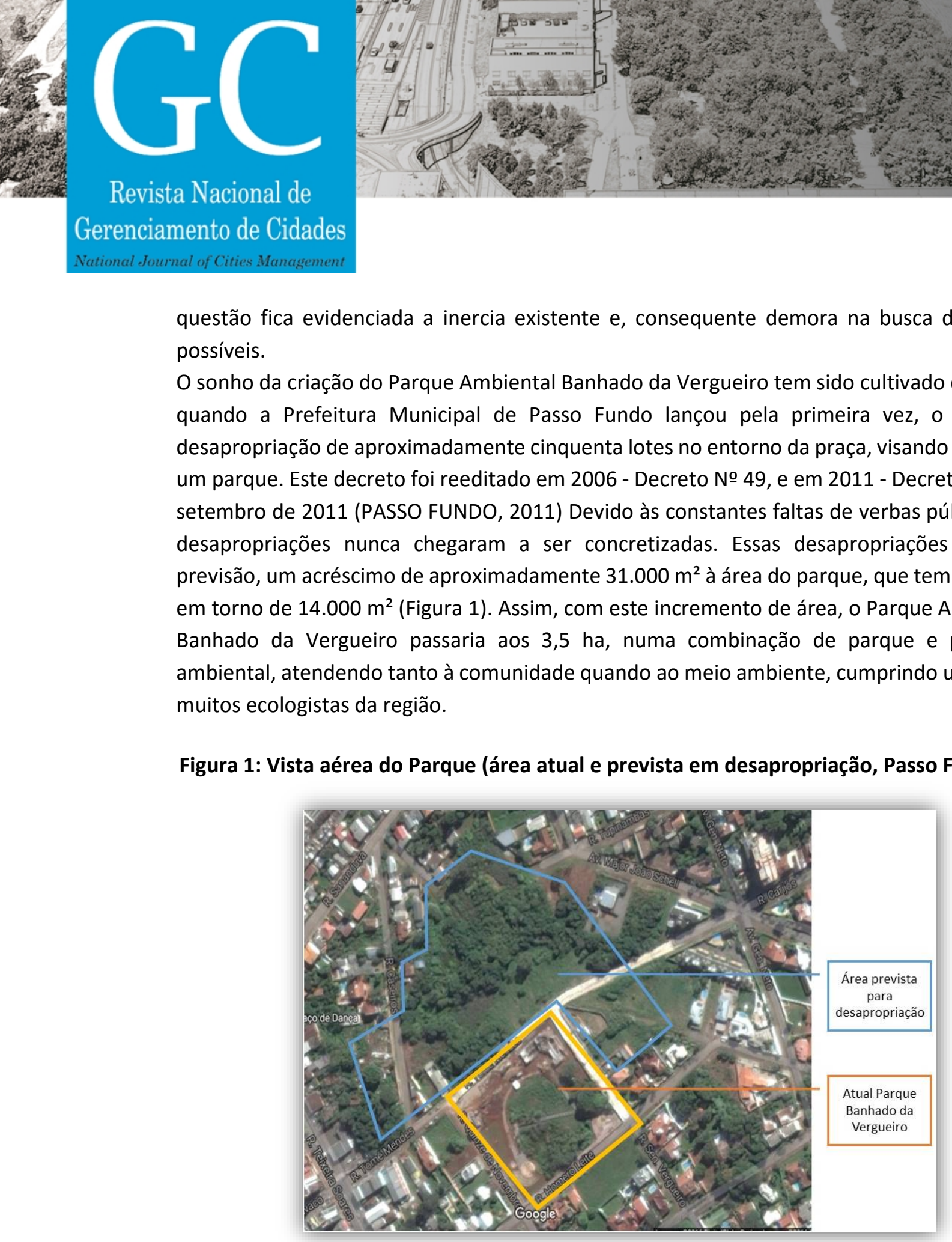

questão fica evidenciada a inercia existente e, consequente demora na busca das soluções possíveis.

O sonho da criação do Parque Ambiental Banhado da Vergueiro tem sido cultivado desde 1941, 作 visando a criação de previsão, um acréscimo de aproximadamente $31.000 \mathrm{~m}^{2}$ à área do parque, que tem atualmente (Figura 1). Assim, com este incremento de area, o Parque Ambiental do e preservação ambiental, atendendo tanto à comunidade quando ao meio ambiente, cumprindo um sonho de muitos ecologistas da região.

Figura 1: Vista aérea do Parque (área atual e prevista em desapropriação, Passo Fundo, 2016

Fonte: Adaptado pelos autores, a partir de Google Earth (2016)

O PDDI (Plano diretor de desenvolvimento integrado de Passo Fundo) institui em seu capítulo II quais deverão ser as especificidades da Qualificação ambiental para o município (PASSO FUNDO, 2006). O desenvolvimento municipal deve estar embasado na valorização do patrimônio ambiental, visando sustentabilidade e promoção dos valores históricos e culturais de Passo Fundo, compreendendo a necessidade de uma relação equilibrada entre ambiente construído e natural. O patrimônio ambiental abrange o patrimônio histórico e cultural e o patrimônio natural e paisagístico; além de integrar o patrimônio histórico e cultural o conjunto de bens imóveis e móveis de valor significativo, ambiências, parques urbanos e 



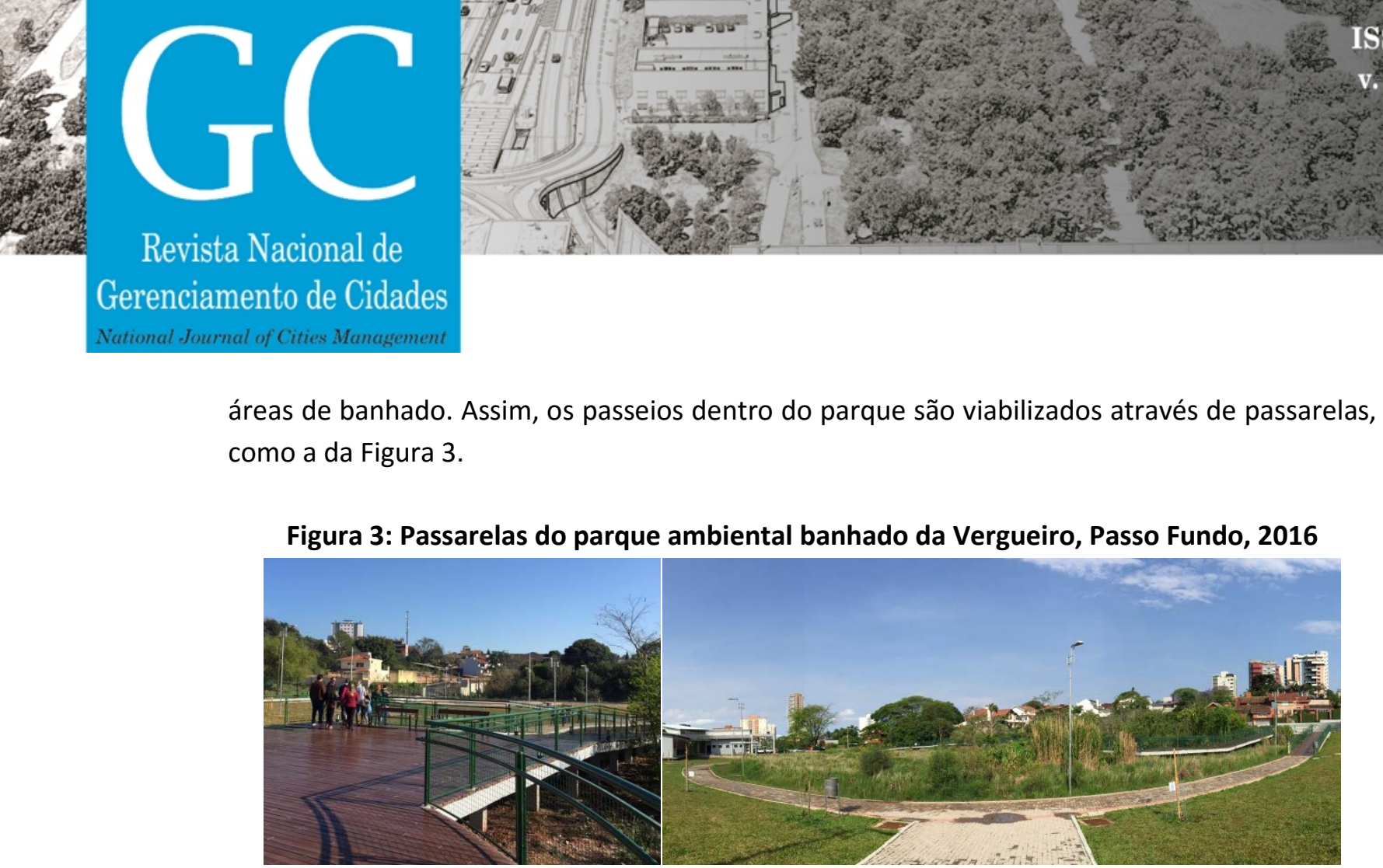

Fonte: autores, 2017

Assim, pode-se perceber que o caminhar sobre a passarela não interfere no ir e vir dos animais sob ela. No parque podem-se imaginar ações de lazer, preservação e educação porque o parque, em seus $14.000 \mathrm{~m}^{2}$ de cenário; provoca pouca intervenção na natureza: passarela que pode ser usada para conhecer o ecossistema, playground com piso emborrachado (Figura 4(a)), permite maior segurança para as crianças e - piso permeável e intertravado, como se observa na Figura 4(b), foram algumas das atividades pensadas e que farão parte da rotina da Secretaria de Meio Ambiente, que tem a sua sede administrativa no parque. $O$ parque prevê também ações de reflorestamento, visando a manutenção das espécies existentes.

Figura 4: Playground do parque com piso emborrachado (a) Estratégias sustentáveis com o piso grama e intertravado (b),2016

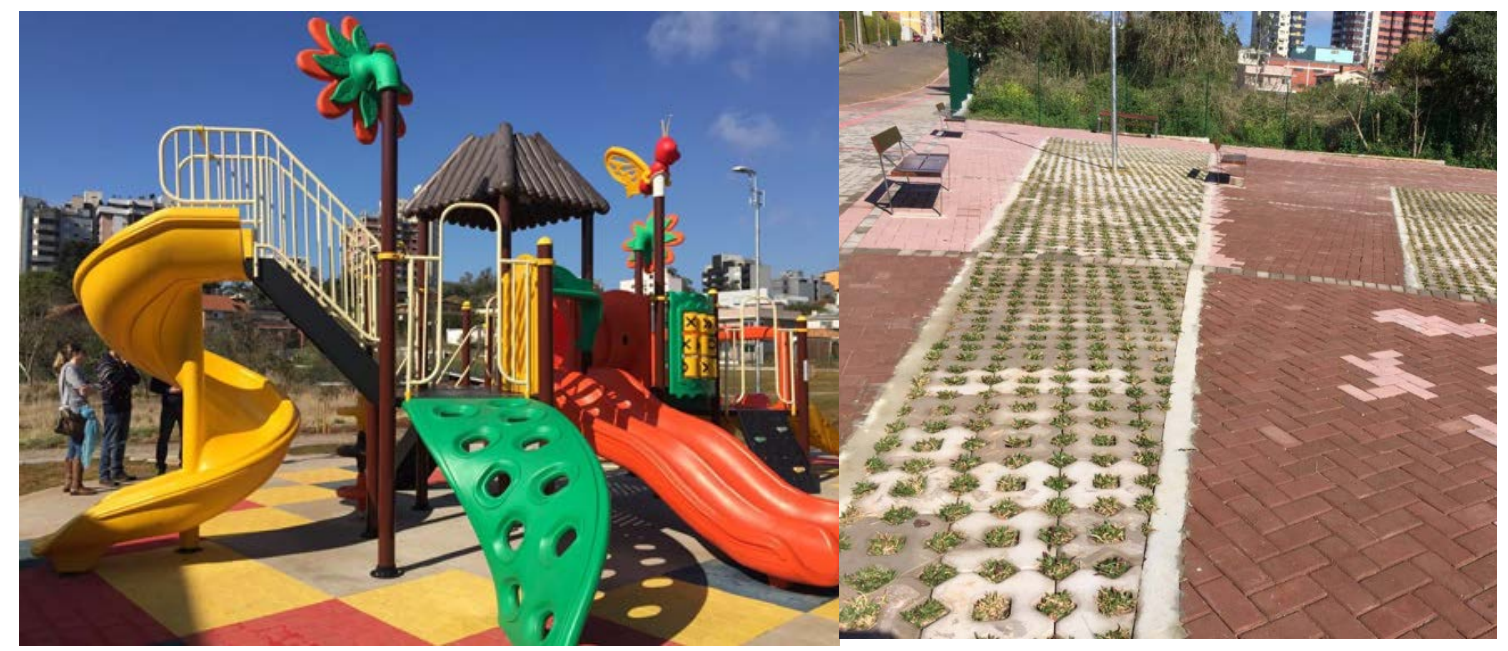

Fonte: autores, 2016 


HERZOG, Cecilia P. Infraestrutura verde. Chegou a hora de priorizar! Minha Cidade, São Paulo, ano 11, n. 130.06, Vitruvius, maio 2011. Disponível em: <http://www.vitruvius.com.br/revistas/read/minhacidade/11.130/3900>. Acesso em: 02 set. 2016.

MELO, Ricardo Henryque Reginato Quevedo. INDICADORES DE SUSTENTABILIDADE PARA UM SISTEMA CICLOVIÁRIO URBANO. 2017. 193 f. Dissertação (Mestrado) - Curso de Pós-graduação em Engenharia Civil e Ambiental, Universidade de Passo Fundo, Passo Fundo, 2017. Disponível em: $<$ http://docs.upf.br/download/ppgeng/2017/ricardo-henryque-reginato-quevedo-melo.pdf>. Acesso em: 10 out. 2017.

PASSO FUNDO. Decreto № 120/2011. Reedita o inteiro teor do decreto N. 49/2006 Que declara de utilidade pública, para fins de desapropriação os imóveis que especifica e dá outras providencias. Disponível em https://leismunicipais.com.br/a/rs/p/passo-fundo/decreto/ 2011/12/120/decreto-n-1202011-reedita-o-inteiro-teor-do-decreto-n-49-2006-que-declara-de-utilidade-publica-para-fins-dedesapropriacao-os-imoveis-que-especifica-e-da-outras-providencias.

Primeiro parque ambiental em área de banhado. PMPF, 30.jun.16. Disponível em < http://www.passofundo.rs.gov.br/interna.php?t=19\&c=11\&i=10828>. Acesso em 16 ago. 2016 . Plano ambiental municipal de Passo Fundo. Passo Fundo: PMPF, 2004.

ROGERS, Richards. Cidade para um pequeno planeta. Barcelona: Gustavo Gilli, 2015.

SÃO PAULO. Parques urbanos municipais de São Paulo: subsídios para a gestão / organização Marussia Whately...[et al.]. -- São Paulo: Instituto Socioambiental, 2008 Disponível em $<$ https://www.socioambiental.org/banco_imagens/pdfs/10367.pdf>. Acesso em 30 ago. 2016

SEMC. Secretaria de Energia, Minas e Comunicações. Atlas Eólico do Rio Grande do Sul. 2002. Disponível em: <http://www.semc.rs.gov.br/atlas/INDEX_geral.htm>. Acessado em 30 ago.2016

SILVA, Janaína Barbossa, PASQUALETTO, Antônio. O caminho dos parques urbanos brasileiros: da origem ao século XXI. Rev. Estudos. Goiânia, v. 40, n. 3, p. 287-298, jun./ago. 2013. <http://revistas.ucg.br/index.php/estudos/article/viewFile/2919/1789> Acesso em 20 ago. 2016

SPINELLI, Juçara. Reestruturação econômica e reprodução do espaço urbano, reflexos sobre o mercado imobiliário de cidades médias, Rio de Janeiro: Geouerj, 2013. Disponível em <http://dx.doi.org/10.12957/geouerj.2013.5342> Acesso em 30 ago. 2016 